\title{
Management Factors Associated with the Occurrence of Uterine Torsion in Buffaloes
}

\author{
Navdeep Singh ${ }^{1}$, Vinod Kumar Gandotra ${ }^{2}$, Sarvpreet Singh Ghuman ${ }^{3}$ \\ Rajsukhbir Singh ${ }^{4}$ and Harish Kumar Verma ${ }^{5}$
}

${ }^{1}$ Directorate of Livestock Farms, Guru Angad Dev Veterinary and Animal Sciences University, Ludhiana-141004

${ }^{2}$ Department of Veterinary Gynaecology and Obstetrics, Guru Angad Dev Veterinary and Animal Sciences University, Ludhiana-141004

${ }^{3}$ Professor-cum-Head, Department of Teaching Veterinary Clinical Complex

${ }^{4}$ Directorate of Extension Education, Guru Angad Dev Veterinary and Animal Sciences University, Ludhiana-141004

*Corresponding author

Keywords

Buffalo, management, floor, uterine torsion, housing

Article Info

Accepted:

15 February 2020 Available Online: 10 March 2020
The purpose of this study was to evaluate the relation of various management and feeding practices with the occurrence of uterine torsion in buffaloes. Five hundred and seven dairy buffalo farmers from 20 districts of Punjab state were surveyed using a questionnaire based on management practices in relation to occurrence of uterine torsion. Extensively reared buffaloes were at lower $(\mathrm{p}<0.05)$ risk of uterine torsion as compared to the stall-fed buffaloes. Daily exercise in the form of walk/wallowing reduced $(p<0.05)$ the risk of uterine torsion. Keeping buffaloes on kacha (mud)floor was associated with lower risk of uterine torsion. However, the segregation of advance pregnant buffaloes and feeding practices had no impact ( $>0.05)$ on the occurrence of uterine torsion. In brief, the rearing of buffaloes in extensive system on kacha(mud) floor along with daily exercise can reduce the incidence of uterine torsion in buffaloes.

\section{Introduction}

Uterine torsion described as the rotation of pregnant uterus on its longitudinal axis (Purohit et al., 2011) has been reported to occur in various species. Out of domesticated ruminants, dairy buffalo is more susceptible to uterine torsion (Foud and El-Sawaf, 1964; El-Naggar, 1978; Ahmed et al., 1980). The incidence of uterine torsion as well as the time of its occurrence in buffaloes emphasizes its impact on dam's health and thus the dairy 
herd profitability. Uterine torsion cases in buffaloes are $67-83 \%$ of the dystocia presented at the referral hospitals (Ghuman, 2010). Usually, uterine torsion occurs before the onset or during the late first stage of parturition as the cervix is partially or completely dilated prior to or immediately after the correction of torsion, and this condition is rarely encountered during the early second stage of parturition (Noakes et al., 2001).

Inappropriate management practices are the important etiological factors for occurrence of uterine torsion especially in rural areas (Sen $e t$ al., 2014;Tripati and Mehta, 2015). However, fewer studies were conducted on the management practices predisposing buffaloes to uterine torsion. The purpose of this study was to evaluate the relation of various management and feeding practices with the occurrence of uterine torsion.

\section{Materials and Methods}

Questionnaire-based survey on occurrence of uterine torsion was carried out on randomly selected 507 dairy buffalo farmers from 20 districts of Punjab state. Dairy farmers/nomads rearing buffaloes reported with uterine torsion and normal parturition was interviewed using comprehensively designed questionnaire. The emphasis was laid on the following management practices for the advance pregnant buffaloes:

\section{System of rearing}

Extensive rearing (Buffaloes reared on pastures as well as kept under loose housing system)

Intensive rearing (Buffaloes reared as stall-fed and remained in tie-barn condition)

\section{Type of floor}

Kaccha(mud) floor (Non-slippery soft surface without bricks)

Pakka floor (Slippery surface made of bricks or concrete)

Mix floor(Provision of both type of flooring)

\section{Daily exercise}

Yes (Walk, minimum 3-4 $\mathrm{Km}$ and/or Wallowing, minimum 30 minute)

No

\section{Segregation of advance pregnant buffalo}

Yes (30 days prior from expected date of calving)

\section{Mineral mixture feeding}

Yes

No

\section{Concentrate feeding}

Yes

No

\section{Statistical analysis}

Data were analyzed by using MINITAB statistical software (release 14.2). Descriptive statistics were calculated to establish frequencies and percentage distribution of various parameters included in the study. Data were first analyzed by Chi-square test $(\chi 2)$ to determine the significance of associations between independent variable and outcome variable(uterine torsion).

All variables with $\mathrm{P}<0.05$ in the initial univariable analysis were considered in a logistic regression analysis. The occurrence of uterine torsion was considered as outcome 
variable. Coefficients, Standard error coefficients, 95\% confidence limits and $\mathrm{P}$ values were mentioned, and significance of results was declared at $\mathrm{p}<0.05$.

\section{Results and Discussion}

Out of 507 buffalo farmers, uterine torsion was recorded in farms of $37.5 \%$ farmers. About $20.5 \%$ farmers were rearing buffaloes in extensive system. This study revealed that stall-fed buffaloes in intensive rearing system were at higher $(\mathrm{p}<0.05)$ risk of uterine torsion as compared to their counterparts (Figure1; Table1). This is in accordance with the previous studies which suggested that the confinement of animals in stables for longer periods may lead to weakness of abdominal muscles and hence occurrence of uterine torsion (Sloss and Dufty, 1980). In stall-fed pregnant cattle which were not segregated from the herd in the housing system were more prone to bumping on sides by the accompanying cattle, one of the reasons for occurrence of uterine torsion (Aubry et al.,
2008).In $17.1 \%$ farms, advanced pregnant buffaloes segregated from the herd. However, the segregation of the buffalo at least one month before the parturition had no impact on the occurrence of uterine torsion as compared to their pregnant counterparts staying in groups till the time of parturition (Figure 1).

About $27.7 \%$ farms were subjecting buffaloes to daily exercise (Table 1). According to the present study, the buffaloes subjected to daily exercise like an hour of wallowing or 3-4 km walk were at lower $(\mathrm{p}<0.05)$ risk of uterine torsion (Figure 1; Table 1). In a previous study, the higher risk of uterine torsion due to lack of exercise was reported (Faria and Simoes, 2015), which could be associated with weakening of the abdominal musculature (Sloss and Dufty, 1980). Moreover the cattle managed on loose housing or extensive rearing tends to have proper exercise (Frazer et al., 1996; Aubry., 2008). On contrary, the incidence of uterine torsion was similar between stall-fed and pastured cattle (Wright, 1958; Desliens, 1967).

Table.1 Multivariate logistic regression results with respect to the risk of having uterine torsion in buffaloes $(\mathrm{n}=507)$

\begin{tabular}{|c|c|c|c|c|c|}
\hline \multirow[t]{2}{*}{ Variables } & \multirow[t]{2}{*}{ Coef. } & \multirow[t]{2}{*}{ SE Coef. } & \multicolumn{2}{|c|}{ 95\% CI } & \multirow[t]{2}{*}{ P-Value } \\
\hline & & & Lower & Upper & \\
\hline \multicolumn{6}{|l|}{ Rearing } \\
\hline Extensive & \multicolumn{5}{|c|}{ Reference } \\
\hline Intensive & 2.37 & 1.09 & 0.23 & 4.52 & 0.030 \\
\hline \multicolumn{6}{|l|}{ Flooring } \\
\hline Pakka & \multicolumn{5}{|c|}{ Reference } \\
\hline Kacha & -0.672 & 0.395 & -1.446 & 0.102 & 0.089 \\
\hline Mix & 0.239 & 0.224 & -0.201 & 0.679 & 0.289 \\
\hline Mix & \multicolumn{5}{|c|}{ Reference } \\
\hline Kacha & -0.911 & 0.380 & -1.655 & -0.167 & 0.016 \\
\hline \multicolumn{6}{|c|}{ Daily exercise } \\
\hline No & \multicolumn{5}{|c|}{ Reference } \\
\hline Yes & -1.888 & 0.471 & -2.812 & -0.965 & 0.0001 \\
\hline
\end{tabular}




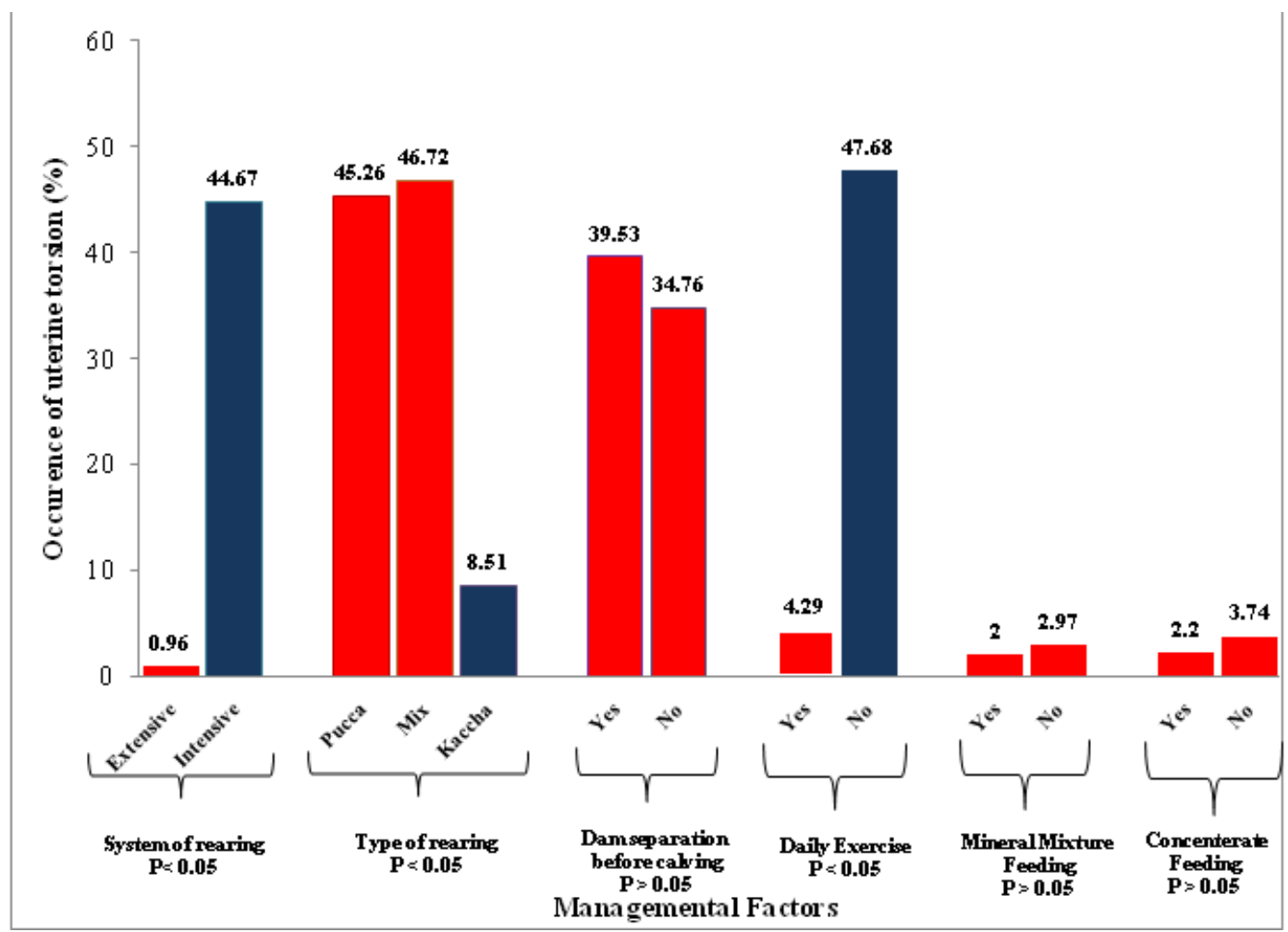

Figure.1 The association of various management factors with occurrence of uterine torsion in buffaloes $(\mathrm{n}=507) .{ }^{*} \mathrm{p}<0.05$, Chi-square analysis

About, $27.1 \%$ farms were keeping buffaloes on pakka floor, $27.8 \%$ on kaccha floor and rest used both kaccha and pakka floor (Table $1)$. The present study recorded that the rearing of buffaloes on kaccha floor reduced $(\mathrm{p}<0.05)$ the risk of uterine torsion as compared to pakka floor and mix floor (Figure 1), which could be due to the chance of animal getting slipped suddenly on pakka floor, thus, making the gravid uterus unstable (Roberts, 1986; Tripathi and Mehta, 2015;Uttam et al., 2015). Mineral mixture and concentrate was fed to the buffalo in $32 \%$ and $70 \%$ farms, respectively. In previous studies, mineral mixture was fed regularly by $16-50 \%$ of the farms in Punjab state (Kasrija and Verma, 2014; Krishandev ., 2016).

The multivariable logistic regression analysis (MLR) revealed that the intensive rearing system $(\mathrm{p}<0.05)$ and lack of daily exercise $(p<0.05)$ lead to an increase in risk of uterine torsion (Table 1). In brief, rearing buffaloes in extensive system on kacha floor along with daily exercise reduces the incidence of uterine torsion in buffaloes.

\section{References}

Ahmed, M.,Chauhary,R.A. andHam, I. H. 1981. Torsion of the uterus as acause of dystocia in the buffaloes. Pak.Vet. J.,1: 22-24.

Aubry, P., Warnick, L.D.,.DesCoteaux,L. and Bouchard, E. 2008.Astudy of 55 field cases of uterine torsion in dairy cattle. Can. Vet. J.,49: 366-372.

Desliens, L. 1967.Uterine torsion in the cow. Etiology andpractical considerations. Bulletin De l'Academie Veterinaire De France 120: 147-56.

El-Naggar, M. 1978. Evaluation of field oriented treatment of uterine torsion in buffaloes in Egypt. Indian Vet. J.,55: 61-67.

Faria, A.S. andSimoes, J. 2015. Incidence of 
uterine torsion during veterinary assisted dystocia and singleton live births after vaginal delivery in HolsteinFriesian cows at pasture. Asian Pac J. Reprod.,4: 309-312

Foud, K. and El-Sawaf, S. 1964. Some observations on torsio-uteri in buffaloes with special reference to its etiological factors. Vet. Med. J. Giz.,9: 173-177.

Frazer, G.S., Perkins,N.R. and Constable, P.D. 1996. Bovine uterine torsion: 164 hospitalreferral cases. Theriogenology, 46: 739-758.

Ghuman, S.P.S.2010. Uterine torsion in bovines: a review. Indian J. Anim. Sci., 80: 289-305.

Kasrija, R. and Verma, H.K. 2014. Practices affecting reproduction (par) score of dairy farmers in western region of Punjab. IndianJ. Anim.Reprod.35 (2):42-46.

Krishandev,Verma,H.K., Kasrija,R. and Singh,J. 2017. Relation between feeding practices and disease incidence in dairy animals of Punjab. Indian $J$. Anim.Reprod.38 (2):59-61.

Noakes, D. E., Parkinson, D. J. and England, G. C. W. 2001.Maternaldystocias. In: Noakes D E (Ed.) Arthurs Veterinary Reproduction and Obstetrics. Saunders Harcourt, India.

Purohit, G.N.,. Barolia, Y, Shekharand, C., Kumar, P.2011. Diagnosis and correction of uterine torsion in cattle and buffaloes. Raksha Technical Review,1: 11-17.

Roberts, S. J. 1986. Diagnosis and treatment of the various types of dystocia. Veterinary Obstetrics and Genital Diseases. pp. 213-17, 230-33, 337-43, 357-59.Woodstock, Edwards Brothers Inc.

Sen, B., Singh, J.,Verma,T. and Patel, P.R. 2014. Performance of growing calves fed on banana (Musa Paradisiaca) stem. The Bioscan, 9: 121-23.

Sloss,V. and Dufty, J.H.1980.Obstetrical physiology. Obstetricalpathology. Obstetrical procedures. Handbook of Bovine Obstetrics. pp. 39, 105, 108-11, 180-83. (Eds)

Srinivas, M., Sreenu,M., Lakshmi Rani,N.,Subramanyam Naidu,K. and Devi Prasad,V. 2007.Studies on dystocia in graded murrah buffaloes: a retrospective study. Buffalo Bull.,26: 40-45.

Tripathi, A. and Mehta, J.S. 2015. Factors associated with uterine torsion in cattle: a retrospective study. The Bioscan,10: 1135-37.

Uttam S, Singh B.,Chaudhary, J.K.,Bassan, S.,kumar, S., and Neha,G. 2015. Analysis of morbidity and mortalityrate in bovine under village conditions of Uttar Pradesh. The Bioscan, 10: 585-91.

Wright, J. G. 1958.Bovine dystocia. Vet. Rec.90: 347-56.

\section{How to cite this article:}

Navdeep Singh, Vinod Kumar Gandotra, Sarvpreet Singh Ghuman, Rajsukhbir Singh and Harish Kumar Verma. 2020. Management Factors Associated with the Occurrence of Uterine Torsion in Buffaloes. Int.J.Curr.Microbiol.App.Sci. 9(03): 2278-2282.

doi: https://doi.org/10.20546/ijcmas.2020.903.258 